\title{
Mechanical Properties of Composites Filled with SMA Particles and Short Fibers
}

Run-xin Zhang ${ }^{\mathrm{a}}$, Qing-Qing Ni ${ }^{\mathrm{b}}$, Toshiaki Natsuki ${ }^{\mathrm{c}}$, Masaharu Iwamoto ${ }^{\mathrm{a}}$

${ }^{a}$ Division of Advanced Fibro-Science,

Kyoto Institute of Technology

Matsugasaki sakyo-ku, Kyoto 606-8585, Japan

${ }^{\mathrm{b}}$ Dept. of Functional Machinery and Mechanics,

Shinshu University,

3-15-1 Tokida, Ueda 386-8567, Japan

${ }^{c}$ Faculty of Engineering, Shinshu University,

Wakasato 4-17-1, Nagano-shi, 380-8553, Japan

* Corresponding author

Prof. Qing-Qing Ni

E-mail: niqq@shinshu-u.ac.jp

Fax: $+81-268-215438$

Tel: $+81-268-215438$ 


\section{ABSTRACT}

Shape memory alloys (SMAs) possess both sensing and actuating functions due to their shape memory effect, pseudo-elasticity, high damping capability and other remarkable properties. Combining the SMAs with other materials can create intelligent or smart composites by utilizing the unique properties of SMAs. In this paper, epoxy resin composites filled with NiTi alloy short fibers and particles were fabricated and their mechanical properties investigated. Owing to the addition of SMA fillers, the flexural rigidity of SMA/epoxy composites increases. Especially, the storage modulus increases remarkably with increasing filler content in the high temperature region. The experimental results show that the addition of just $3.5 \%$ of SMA fillers to epoxy resin resulted in a remarkable increment of storage modulus, which is six times as large as that of epoxy bulk (ER3). The storage modulus reaches the maximum at the SMA phase transformation temperature of approximate $120^{\circ} \mathrm{C}$. The loss factor of SMA/ER3 composites increases with the increment of SMA filler contents. Based on the Halpin-Tsai theory, moreover, a model for the laminated plates with SMA fillers is presented to predict the dynamic mechanical properties. Compared to the experimental results, reasonable prediction of the dynamic behavior is obtained based on the present models.

Key Words: Shape memory alloy; Composites; Mechanical properties; Dynamic response 


\section{Introduction}

Shape memory alloys (SMAs) have been the subject of active research for over three decades due to their unique attributes and the resulting potential for many applications [1-2]. Early work focused mainly on the characterization and discovery of the mechanical phenomena for their unique properties. Recently, studies and development of SMA composites. have seen significant growth because SMAs possess both sensing and actuating functions leading to many potential applications. Combining the properties of SMAs with other materials can create intelligent or smart composites by utilizing the unique properties of SMAs, such as shape memory effect, pseudo-elasticity, high damping capability. Recently, SMA wires have also become commercially available for the design of smart composite structures because SMA wires with small diameter fibers and particles can be easily produced.

Many studies have shown that SMA composites have significant potential applications for vibrational and structural controls [3-6]. A preliminary study of weaving SMA wires has been reported by Boussu et al. [7]. They made the woven SMA fabric using NiTi fine wires of 0.15 $\mathrm{mm}$ diameter. Unfortunately, practical details of the fabrication are not disclosed. The textile composites with a smart SMA-Base seems to be quite promising since the tremendous diversity of textile architecture allows the SMA components to easily fabricate their various forms. For example, SMA wires or yarns can be used as "smart fibers" combined with conventional glass/carbon fibers so as to make a part of the textile perform multi-functional properties [8]. Although SMA textile composites are able to control the actuator function by careful designing the shapes of SMA textile, it is difficult for the processing of SMAs into textile structures with special shapes. The interfacial failure between the SMAs and the resin occurs easily because the fabrication process results in high residual stress within the SMA composites when cooled down to room temperature. However, discontinuous SMAs have an advantage of dispersing the residual stress because of the random distribution of SMA fillers in 
epoxy resin matrix. On the other hand, the discontinuous SMA composites can be easily fabricated by hand-layup methods at low-cost.

To authors' knowledge, few studies were reported on composites filled with SMA short fibers or SMA particles [9]. The main objective of this study is to investigate the actuating function of the SMA composites with embedded discontinuous fillers. The SMA composites were fabricated using both TiNi alloy short fibers and particles. In order to enforce the active function of the SMA composites, the laminated composites were designed with two layers: an epoxy bulk layer and a SMA reinforced layer. The static and dynamic flexural properties of the SMA composites are investigated since the flexural behavior is more important for the laminated structures. Moreover, a model for the laminated plates with SMA fillers is presented to predict the dynamic mechanical properties. The microstructure comparison between the SMA fibers and particles was analyzed and discussed.

\section{Experimental Procedures}

\subsection{Materials}

The SMAs in the present study were Ti-Ni alloy $(\mathrm{Ti}: \mathrm{Ni}=50: 50)$ produced by Pure Material Laboratory Co., Ltd., Japan. The average diameters of SMA particles were $425 \mu \mathrm{m}$. Ti-Ni alloy (KIOKALLOY-R) with short fibers had the diameter $0.2 \mathrm{~mm}$ and the length $1.5-2 \mathrm{~mm}$, produced by Daido Steel Co., Ltd. Japan. The phase transformation temperature for austenite of the Ti-Ni alloy is about $58{ }^{\circ} \mathrm{C}$. The polymer used as a matrix was ER3 epoxy resin, and the hardening agent was EH208W produced by GHCRFT Co., Ltd., Japan. The ER3 epoxy resin had a high impact resistance property, and the glass transition temperature $\left(T_{g}\right)$ was approximately $140^{\circ} \mathrm{C}$. The engineering constants of Ti-Ni alloy and ER3 epoxy resin were listed in Table 1.

\subsection{Specimen fabrication}


After the SMA fillers (particles or fibers) were well dispersed into ER3 epoxy resin, the mixed samples were dried for $20 \mathrm{~min}$ by a vacuum pump. The resin was then poured into a mold and cured at room temperature for 24 hours. Finally, the molding was moved to a heating oven and heated from $40{ }^{\circ} \mathrm{C}$ to $140{ }^{\circ} \mathrm{C}$ at a rate of $10{ }^{\circ} \mathrm{C} / \mathrm{hr}$. Then, two-layer composites of the epoxy bulk layer and SMA filler-reinforced layer were molded. The thickness of samples was $1.2 \mathrm{~mm}$. The weight content of SMA fillers are $1 \%, 1.5 \%, 3.5 \%, 5.1 \%, 16.1 \%$ and $27.4 \%$, respectively, which were represented by $1 \mathrm{wt} \%, 2 \mathrm{wt} \%$, and so on.

\subsection{Experimental tests}

The samples $40 \times 5 \times 1.2 \mathrm{~mm}$ were cut out, and flexural tests and dynamic mechanical experiments were carried out. Three-point bending tests were performed using Instron Universal Machine (Model 4466). The cross-head speed was $1 \mathrm{~mm} / \mathrm{min}$ during loading with the span length of $30 \mathrm{~mm}$. Experimental data of the dynamic mechanical properties were collected at synthesis frequencies of $10,20,40,80$, and $160 \mathrm{~Hz}$, and at temperature from 0 to $250{ }^{\circ} \mathrm{C}$ at the rate of $2{ }^{\circ} \mathrm{C} / \mathrm{min}$. The dispersion of SMA particles and short fibers can be observed using digital HF microscope (KEYENCE, VH-8000).

\section{Theoretical analysis of dynamic properties}

In the solution of dynamic properties, the complex elastic moduli are used if it is assumed that the according to elastic-viscoelastic principle. For discontinuous fiber-reinforced laminated plates, we present a theoretical approach of the dynamic properties based on Halpin-Tsai equations. For the composites filled with SMA particles, the theoretical approach can still be used if we assume that the fiber aspect ratio is equal to one.

\subsection{Storage modulus and loss factor in SMA filler layer}

The elastic moduli for non-continous unidirectional fiber-reinforced composites can be 
estimated from Halpin-Tsai equation [10]. The complex moduli along the longitudinal and transverse directions can be represented by

$$
\begin{aligned}
& E_{L}^{*}=\frac{E_{m}^{*}\left(1+2 \xi \eta_{L}^{*} V_{f}\right)}{1-\eta_{L}^{*} V_{f}}, \quad \xi=\Gamma \backslash D, \\
& E_{T}^{*}=\frac{E_{m}^{*}\left(1+2 \eta_{T}^{*} V_{f}\right)}{1-\eta_{T}^{*} V_{f}},
\end{aligned}
$$

and

$$
\begin{aligned}
& \eta_{L}^{*}=\frac{E_{f}^{*} / E_{m}^{*}-1}{E_{f}^{*} / E_{m}^{*}+2 \xi}, \\
& \eta_{L}^{*}=\frac{E_{f}^{*} / E_{m}^{*}-1}{E_{f}^{*} / E_{m}^{*}+2},
\end{aligned}
$$

where the complex modulus $E^{*}=E^{\prime}+i E^{\prime \prime}$, in which $E^{\prime}$ and $E^{\prime \prime}$ is the storage and loss moduli. $E_{f}^{*}$ and $E_{m}^{*}$ are the complex moduli of the SMA fibers and the epoxy bulk, respectively. $V_{f}$ is the volume fraction of the fibers. $L$ and $D$ are the fiber length and diameter, respectively.

For the composites with randomly oriented discontinuous fibers in two dimensions, the complex modulus is given by

$$
E_{c}^{*}=\frac{3}{8} E_{L}^{*}+\frac{5}{8} E_{T}^{*}
$$

From above equations, therefore, we obtain the storage modulus and the loss factor:

$$
E_{c}^{\prime}=\frac{3}{8} \frac{E_{m}^{\prime}\left(1+2 \xi \eta_{L}^{\prime} V_{f}\right)}{1-\eta_{L}^{\prime} V_{f}}+\frac{5}{8} \frac{E_{m}^{\prime}\left(1+2 \eta_{T}^{\prime} V_{f}\right)}{1-\eta_{T}^{\prime} V_{f}},
$$




$$
\begin{aligned}
\tan \delta_{c} & =\frac{E_{c}^{\prime \prime}}{E_{c}^{\prime}} \\
& =\frac{3 \tan \delta_{m}\left(1+2 \xi \eta_{L}^{\prime \prime} V_{f}\right)\left(1-\eta_{T}^{\prime \prime} V_{f}\right)+5 \tan \delta_{m}\left(1+2 \eta_{T}^{\prime \prime} V_{f}\right)\left(1-\eta_{L}^{\prime \prime} V_{f}\right)}{3\left(1+2 \xi \eta_{L}^{\prime \prime} V_{f}\right)\left(1-\eta_{T}^{\prime} V_{f}\right)+5\left(1+2 \eta_{T}^{\prime} V_{f}\right)\left(1-\eta_{L}^{\prime} V_{f}\right)} \bullet \frac{\left(1-\eta_{L}^{\prime} V_{f}\right)\left(1-\eta_{T}^{\prime} V_{f}\right)}{\left(1-\eta_{L}^{\prime \prime} V_{f}\right)\left(1-\eta_{T}^{\prime \prime} V_{f}\right)}
\end{aligned}
$$

and

$$
\begin{gathered}
\eta_{T}^{\prime \prime}=\frac{\left(E_{f}^{\prime} / E_{m}^{\prime}\right) \tan \delta_{f}-\tan \delta_{m}}{\left(E_{f}^{\prime} / E_{m}^{\prime}\right) \tan \delta_{f}+2 \xi \tan \delta_{m}} \\
\eta_{T}^{\prime}=\frac{E_{f}^{\prime} / E_{m}^{\prime}-1}{E_{f}^{\prime} / E_{m}^{\prime}+2 \xi}, \\
\eta_{T}^{\prime \prime}=\frac{\left(E_{f}^{\prime} / E_{m}^{\prime}\right) \tan \delta_{f}-\tan \delta_{m}}{\left(E_{f}^{\prime} / E_{m}^{\prime}\right) \tan \delta_{f}+2 \tan \delta_{m}}, \\
\eta_{T}^{\prime}=\frac{E_{f}^{\prime} / E_{m}^{\prime}-1}{E_{f}^{\prime} / E_{m}^{\prime}+2},
\end{gathered}
$$

where $\tan \delta_{f}$ and $\tan \delta_{m}$ are the loss factors of the SMA and ER3 epoxy, respectively.

\subsection{Storage modulus and loss factor of SMA/ER3 composites}

Figure 1 shows a model for SMA/ER3 composites with SMA and ER3 layers. According to composite-beam theory, the flexural modulus and the loss factor of composites is given by

$$
\begin{aligned}
E^{\prime} & =\left(E_{C}^{\prime} I_{C}+E_{m}^{\prime} I_{m}\right) / I, \\
\tan \delta & =\frac{E^{\prime \prime}}{E^{\prime}}=\frac{E_{C}^{\prime} I_{C} \tan \delta_{C}+E_{m}^{\prime} I_{m} \tan \delta_{m}}{E_{C}^{\prime} I_{C}+E_{m}^{\prime} I_{m}}
\end{aligned}
$$

where $I, I_{c}, I_{m}$ are the moment of inertia of the cross section in two-layer composites, the SMA filler layer, and the epoxy bulk layer, respectively, and they are given by

$$
\begin{aligned}
& I_{c}=\frac{1}{3}\left[\left(t_{c}-e\right)^{3}+e^{3}\right] \\
& I_{m}=\frac{1}{3}\left[\left(t_{c}+t_{m}-e\right)^{3}-\left(t_{c}-e\right)^{3}\right] \\
& I=\frac{1}{3}\left[\left(t_{c}+t_{m}-e\right)^{3}+e^{3}\right]
\end{aligned}
$$

and the mid-plane for two-layer composites is obtained from 


$$
e=\frac{E_{c} t_{c}^{2}+E_{m} t_{m}\left(2 t_{c}+t_{m}\right)}{2\left(E_{c} t_{c}+E_{m} t_{m}\right)}
$$

where $t_{c}$ and $t_{m}$ are the thickness of SMA filler layer and epoxy bulk layer, respectively.

\section{Results and Discussion}

\subsection{Microstructural observation}

High quality mixing of SMA fillers within the matrix is an important parameter. Figure 2 shows the surface observation of SMA filler layers using digital HF microscope. The images shown in Figs. 2 (a) and (b) are the surface of the SMA particle layer with $5.1 \mathrm{wt} \%$ and 27.4 $w t \%$, respectively. In order to compare with the particle SMAs, Figs. 2(c) and (d) show the images for the SMA short fiber layer under the same filler weight contents. Black and blank parts in the images of Fig. 2(b) indicate the epoxy resin and fillers, respectively, while black and blank parts in the images of Figs. (a), (c) and (d) represent respectively the fillers and epoxy resin due to image reverse. The uniform random dispersions of SMA fillers were observed from these images although occasional small aggregates exist in some regions.

\subsection{Mechanical properties of SMA/ER3 composites}

\subsubsection{Flexural properties}

Figure 3 shows representative curves of loading and deflection for SMA filler (short fiber and particles) composites at room temperature. The loading-deflection response of the SMA filler composites appears to be an approximately linear relationship. The fracture deflection of SMA filler composites decreases with increasing SMA filler weight content. These results suggest that the SMA filler composites show brittle fracture behavior.

\subsubsection{Dynamic mechanical properties (DMA)}

For the SMA filler (short fiber and particles) composites, the effects of filler contents on the storage modulus are investigated as shown in Figs. 4(a) and (b). It is found that the storage 
moduli of SMA filler composites are affected largely by the SMA filler content. An addition of SMA fillers into an epoxy resin results in considerable increment of modulus in SMA composites, particularly over the austenite transformation temperature, $80{ }^{\circ} \mathrm{C}$, of $\mathrm{TiNi}$ alloys. Below the temperature of $80^{\circ} \mathrm{C}$, the storage moduli of SMA composites decrease with increasing temperature. However, they increase dramatically during the temperature range from $80{ }^{\circ} \mathrm{C}$ to $120^{\circ} \mathrm{C}$. This is mainly because the stiffness of SMA filler becomes large after the phase transformation from martensite to austenite. Seeing the values of storage modulus at $120{ }^{\circ} \mathrm{C}$ shown in Fig. 4, when SMA filler contents is less than $3.5 \mathrm{wt} \%$ the storage modulus increases with increasing filler weight content, but it decreases inversely with SMA filler content larger than $3.5 \mathrm{wt} \%$. This may suggest that an optimal content of SMA fillers exists in the SMA filler composites. Figure 5 shows the change of the storage modulus between the start and finish temperatures of austenite phase transformation as a function of SMA filler contents. It is found that the amount of $3.5 \mathrm{wt} \%$ is a key point for the change in the storage modulus from increment to decrement during the phase transformation. This may be explained by the interaction due to thermally induced stresses between the filler and matrix [11]. In the high temperature region over a certain limit, the residual thermal stress around fillers decreases with increasing filler contents. This implies that the interfacial strength between fillers and matrix becomes small. Therefore, the stiffness ratio (SMA vs. ER3) in SMA/ER3 composites decreases with increasing filler contents. The temperature history in SMA/ER3 composites is confirmed by the change in storage modulus from about $80{ }^{\circ} \mathrm{C}$ to $120{ }^{\circ} \mathrm{C}$ (see Fig. 6) [12].

Figure 6 shows the normalized storage moduli versus temperature for different SMA filler contents. SMA shapes also affect the storage modulus although the variation of the storage modulus with temperature is similar to each other for SMA short fibers and particles. To clarify the effect of SMA fillers on the storage moduli, the data in Fig. 4 were normalized by that of the epoxy resin. It is obvious that the effect of embedded SMA fillers on the storage 
modulus is significant. The addition of SMA particles exhibits larger effect on the modulus than that of the SMA short fibers, especially when the temperature ranges from $40^{\circ} \mathrm{C}$ to $80^{\circ} \mathrm{C}$. At the SMA phase transformation temperature of approximate $120^{\circ} \mathrm{C}$, only $3.5 \mathrm{wt} \%$ of SMA fillers result in the increment of storage modulus for about six times as large as that in epoxy bulk.

Figure 7 shows the predicted values of storage modulus according to the Eq.(13) in the previous model analysis. The predicted values are lower than the experimental results, and the difference between analysis and experiments is significant especially at high temperature beyond $80^{\circ} \mathrm{C}$. Although a striking difference existed between the predicted and the experiment results, a similar tendency for the storage modulus with the variation of both temperature and filler contents is observed. The increasing tendency of storage modulus around the SMA phase transformation temperature is partly predicted.

The loss factors of the SMA composites are shown in Fig. 8. The loss factors $\tan \delta$ have maximum peaks when the SMA composites are heated through the glass transition region of epoxy resin around $140^{\circ} \mathrm{C}$. The peaks shift to a slightly lower temperature when SMA filler contents increase and this indicates that the glass transition temperature of the composites becomes low by the addition of SMA fillers. The loss factors versus the temperature in SMA/ER3 composites are predicted as shown in Fig. 9. The predicted values of loss factors agree reasonably with the experimental results although the variation of glass transition temperature in experiments is not taken into account.

Figure 10 shows the peak values in the $\tan \delta$ curves from experiments plotted as a function of SMA filler contents. It is found that the SMA particle composites exhibits larger loss factors than the SMA short fiber composites. The tan $\delta$ peaks for both SMA filler composites increase with an increase in SMA filler contents. It is found that both curves in Fig. 10 with a parallel increase tendency to the change in filler contents, and their difference for tan 
$\delta$ is about 0.07 for any filler content. The loss factor of the SMA composite for filler content of $27.4 \mathrm{wt} \%$ is about $20 \%$ larger than that for $1.5 \mathrm{wt} \%$. This may be due to the following reason. The average diameters of the discontinuous fiber and the particle are $0.2 \mathrm{~mm}$ and $0.425 \mathrm{~mm}$, respectively. Due to the friction between the filler and the matrix during vibration process, it is possible to convert the vibration energy into the thermal energy. Moreover, the friction also exists between fillers when the filler content is large. The damping coefficient, therefore, may increase with increasing filler content [13].

\section{Conclusions}

The SMA composites filled with both SMA particles and SMA short fibers are fabricated. In order to enforce the active function of the SMA composites, the laminated composites with two layers were designed and the static and dynamic mechanical properties investigated. The results suggest that the SMA composites improve the dynamic property, even only by the addition of small amounts of SMA fillers. The experimental results show that the addition of just $3.5 \%$ of SMA fillers to epoxy resin resulted in the maximum increment of storage modulus as large as six times of epoxy bulk in the glass transition region. Moreover, the loss factor of the fiber SMA composites increases with increasing filler contents. The SMA particle composites exhibit higher loss factors than the SMA fiber composites. Based on the present model, the predicted values of dynamic properties agree reasonably with the experimental results. According to this work, a development of smart composites with vibration controls may be expected by using embedded SMA fillers.

Acknowledgements--This project is partly supported by the fund of 21st Century COE Program (Japanese government) - Advanced fiber science and textile technology in Shinshu university. 


\section{References}

[1] Z.G. Wei, C.Y. Tang, W.B. Lee, Design and fabrication of intelligent composites based on shape momory alloys, Journal of Materials Processing Technology, 69, (1997) 68-74

[2] N. Ma, G. Song, Control of Memory Alloy Actuator Using Pulse Width (PW) Modulation, Smart Structures and Materials 2002: Modeling, Signal Processing, and Control, Vittal S. Rao, Editor, Proceedings of SPIE Vol. 4693, (2002) 348-359

[3] M.C. Piedboeuf, R. Gauvin, M. Thomas, Damping behaviour of shape memory alloys: strain amplitude, frequency and temperature effects, Journal of Sound and Vibration, Vol. 214, No.5, (1998)855-901

[4] Kin-tak, lau, Vibration characteristics of SMA composite beams with different boundary conditions, Materials and Design, 23, (2002) 741-749

[5] W.M. ostachowicz, S. Kaczmarczyk, Vibrations of composite plates with SMA fibers in a gas stream with defects of the type of delamination, Composite Structures 54, (2001) 305-311

[6] J.S. Park, J.H. Kim, S.H. Moon, Vibration of thermally post-buckled composites embedded with shape momory alloy fibers, Composite Structures 63, (2004) 179-188

[7] F. Boussu, G. Bailleul G, JL. Petitniot, H. Vinchon, Development of shape memory alloy fabrics for composite structures, AUTEX Res J 2, (2002) 1-7

[8] R. X. Zhang, Q.Q. Ni, A. Matusda, T. Yamamura, M. Iwamoto, Vibration Characteristics of Laminated Composite Plates with Embedded Shape Memory Alloys, Composite structures, in press, Available online 9 J une 2005.

[9] G. Mulasawa, T. Tohgo, H. Ishii, Deformation Behavior and Fracture Process of NiTi/polycarbonate Shape Memory Alloy Composites under Thermo-Mechanical Loading, Japan Society of Mechanical Engineers, A 66-650, (2000) 83-89

[10] J. Biagiotti, S. Fiori, L. Torre, Mechanical Properties of polypropylene matrix composites reinforced with natural fibers:A statistical approach, Polymer composites, 25(1), (2004) 26- 36.

[11] S.N. Nazhat, R. Joseph, M. Wang, R. Smith, K.E. Tanner, W. Bonfield, Dynamic mechanical characterization of hydroxyapatite reinforced polyethylene: effect of particle size, Journal of Materials Science: Materials in Medicine, 11, $625(2000)$ 
[12] R. I. Todd, A. R. Boccaccini, Theamal residual stresses and their toughening effect in $\mathrm{AL}_{2} \mathrm{O}_{3}$ platelet reinforced glass, Acta mater. Vol. 47, 11, 3236 (1999)

[13] T.N. Aoki, T. Inoue, High performance polymer alloy, MARUZAN Pub. Co., 140-152(1994) 
Figure captions

Fig. 1 Calculation model for SMA/ER3 composites

Fig. 2 Surface observation of samples for SMA particles and SMA short fiber with 5.1wt\% and $27.4 \mathrm{wt} \%$, respectively.

Fig. 3 Loading-deflection curves for SMA/ER3 composites.

Fig. 4 Storage modulus in SMA composites with different SMA filler weight contents.

Fig. 5 Variation of the storage modulus for different filler contents between $80^{\circ} \mathrm{C}$ and $120^{\circ} \mathrm{C}$.

Fig. 6 Normalized storage modulus by ER3 epoxy bulk.

Fig. 7 Theoretical prediction of Storage modulus

Fig. 8 Loss factor tan $\delta$ as a function of SMA filler contents in experiments

Fig. 9 Theoretical prediction of loss factor tan $\delta$.

Fig. 10 The peak values for loss factor in both SMA particles and SMA short fiber composites.

Table 1 Material constants 
Figure 1

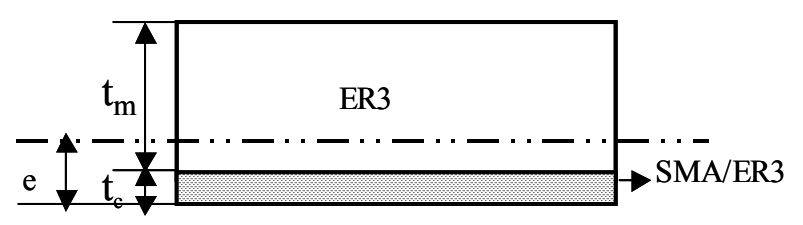


Figure 2

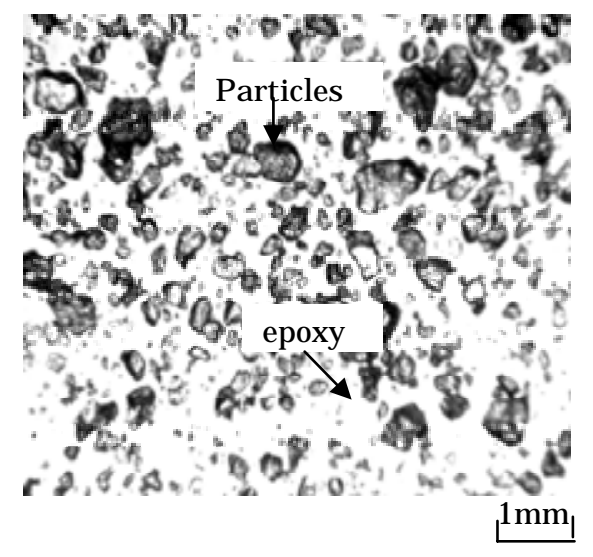

(a) $5.1 \mathrm{wt} \%$ (particles)

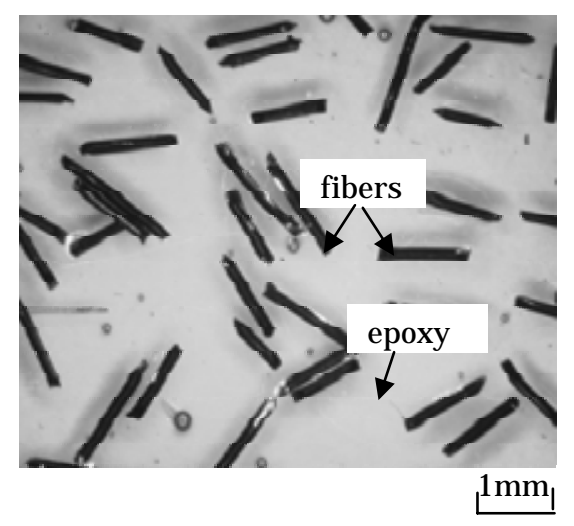

(c) $5.1 \mathrm{wt} \%$ (short fiber)

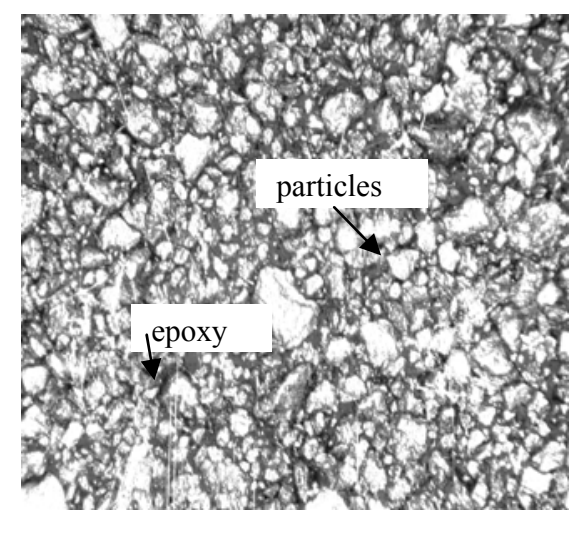

(b) $27.4 \mathrm{wt} \%$ ( particles)

$1 \mathrm{~mm}$

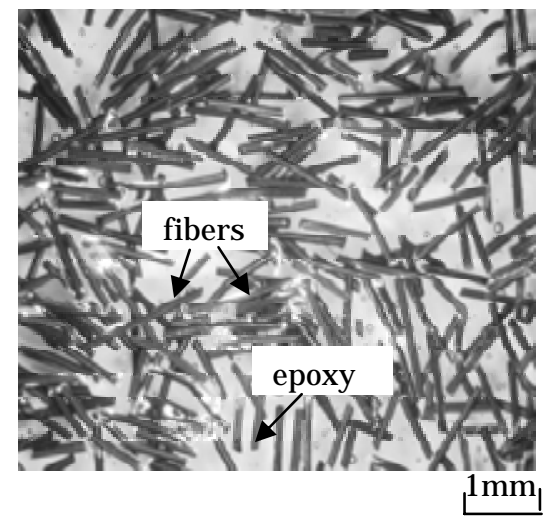

(d) $27.4 \mathrm{wt} \%$ (short fiber) 
Figure 3

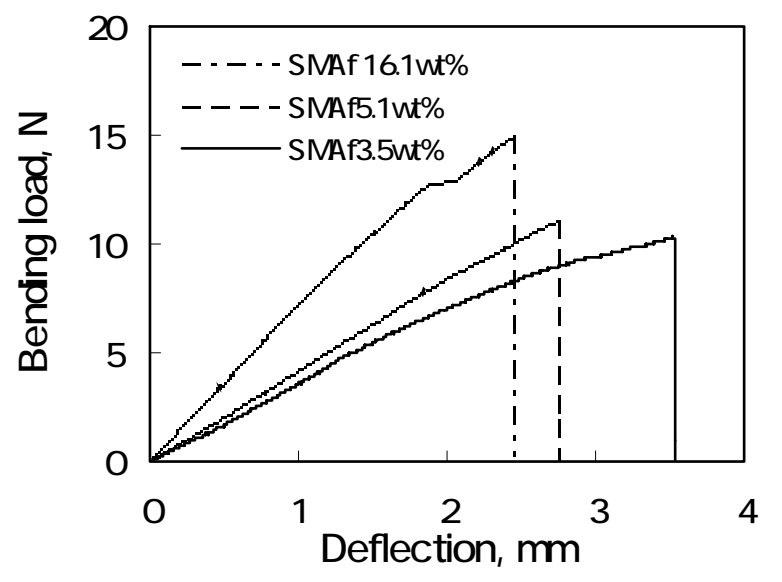

(a) SMA short fiber composites

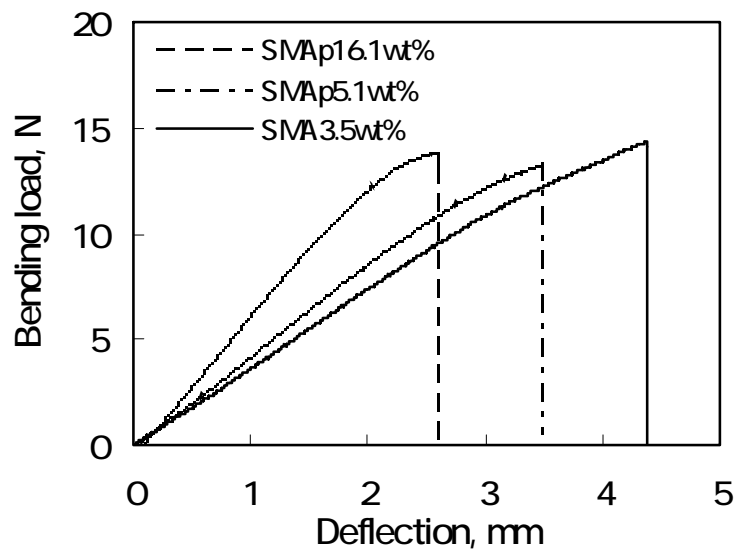

(b) SMA particle composites 
Figure 4

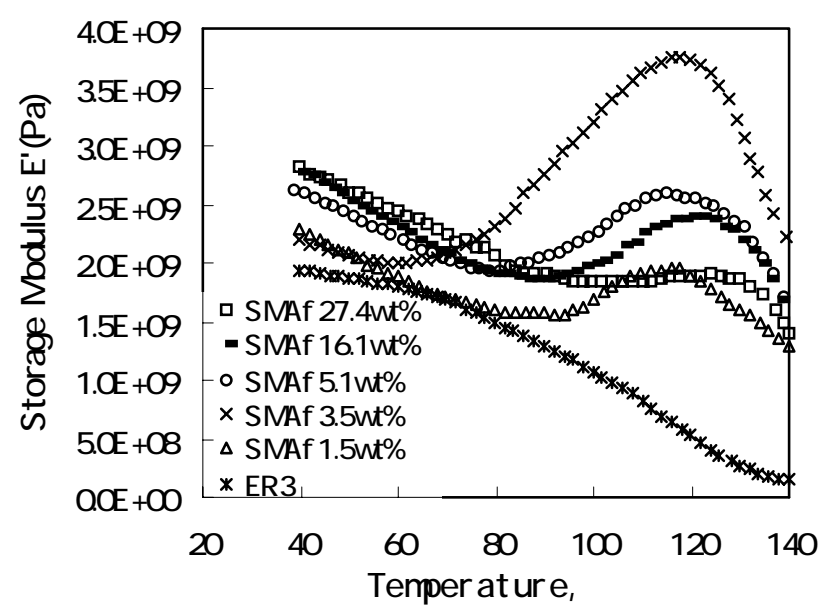

(a) SMA short fiber composites

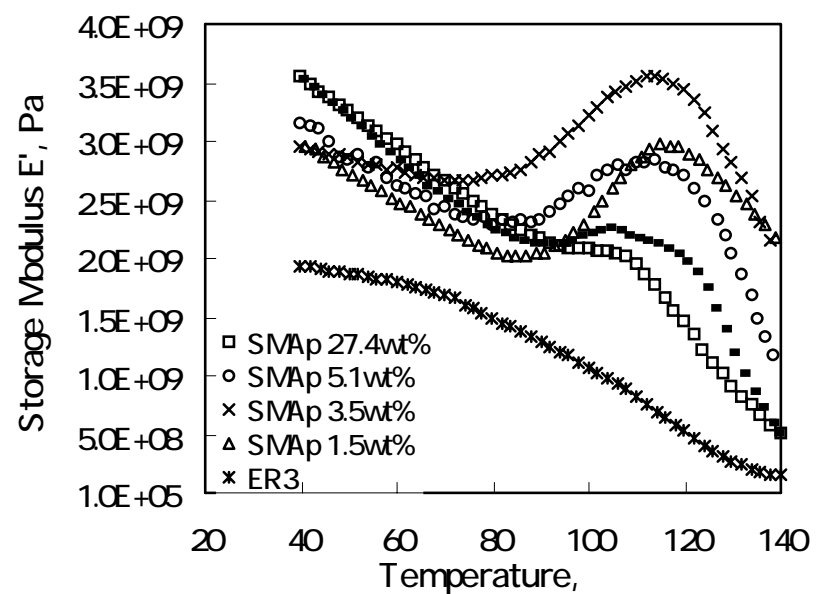

(b) SMA particle composites 
Figure 5

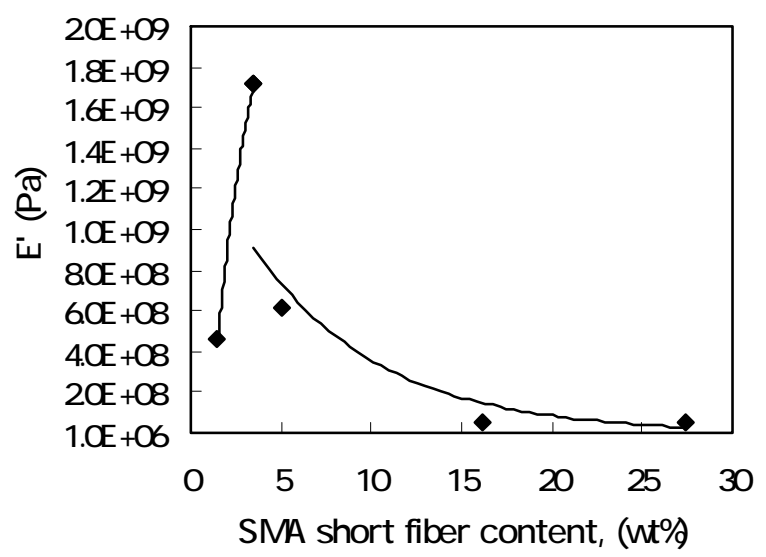

(a) SMA short fiber composites

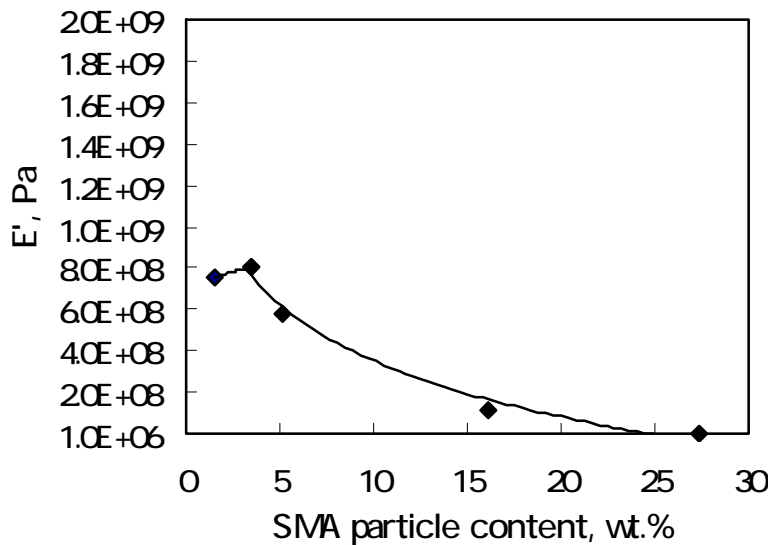

(b) SMA particle composites 
Figure 6

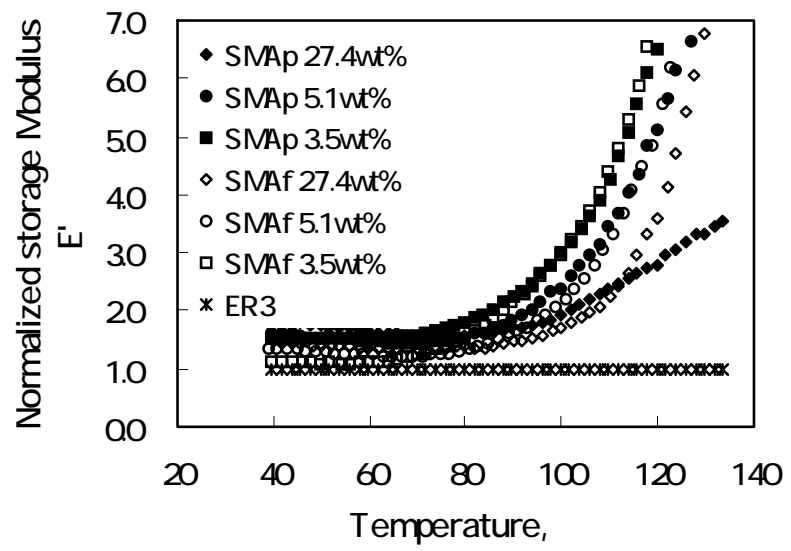


Figure 7

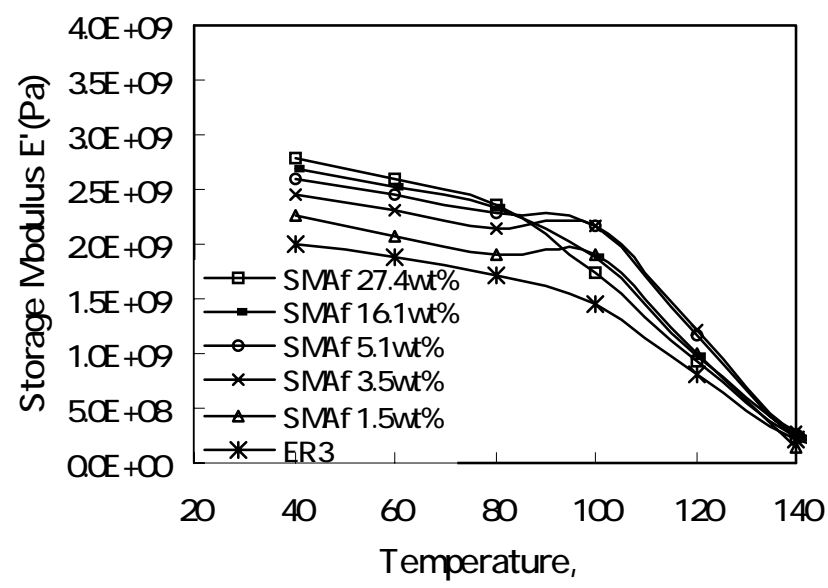

(a) SMA short fiber composites

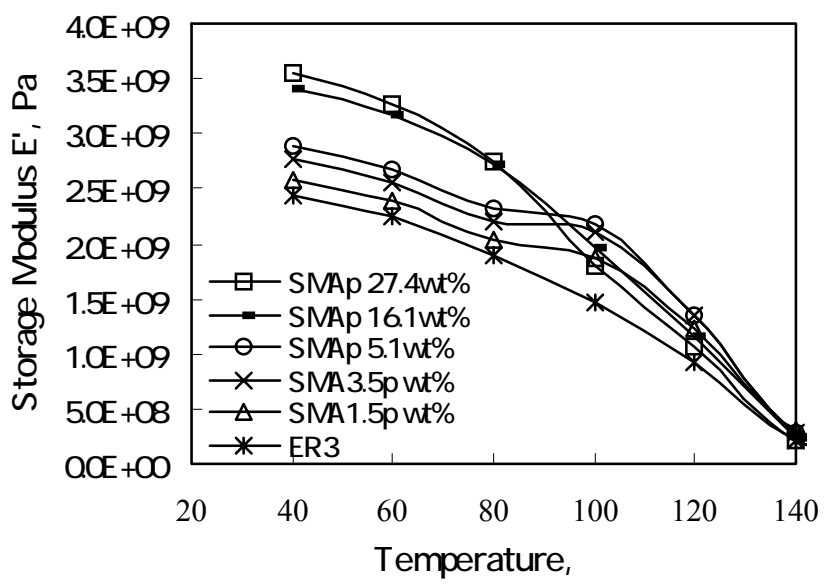

(b) SMA particle composites 
Figure 8

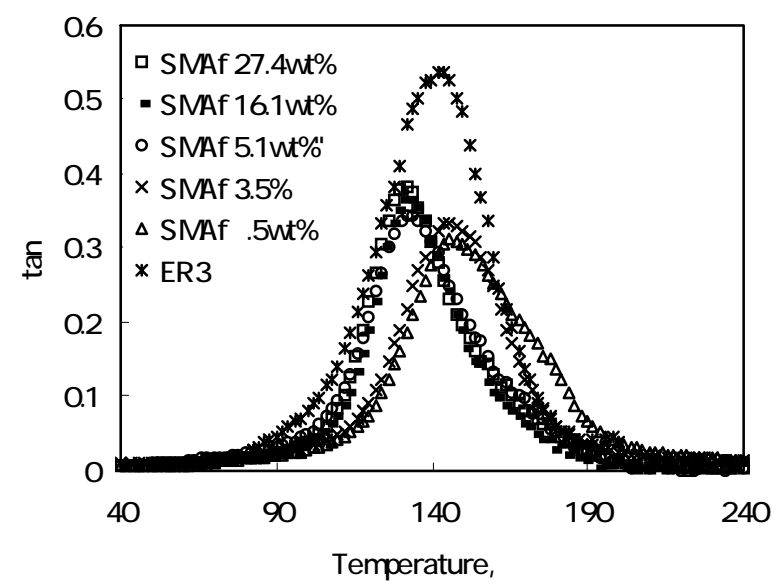

(a) SMA short fiber composites

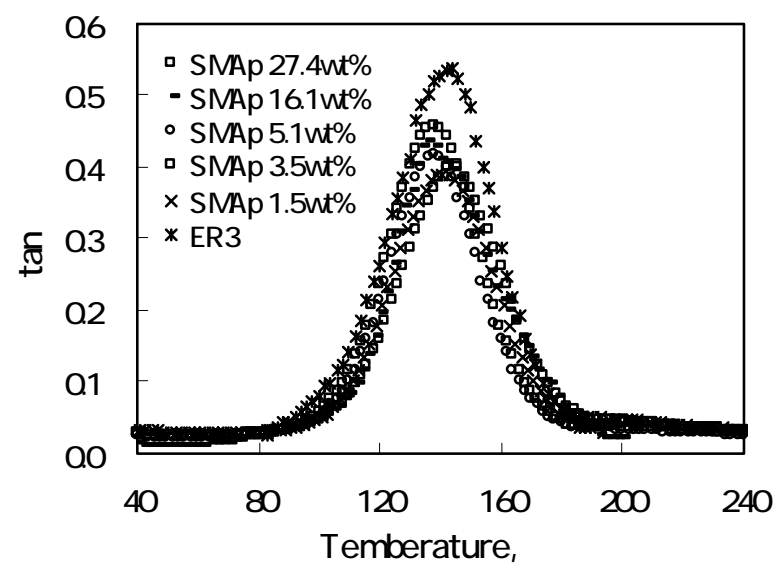

(b) SMA particle composites 
Figure 9

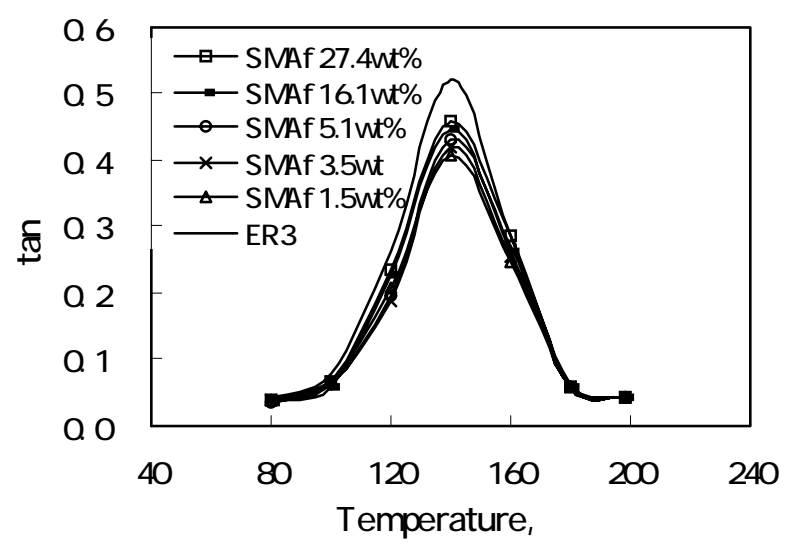

(a) SMA short fiber composites

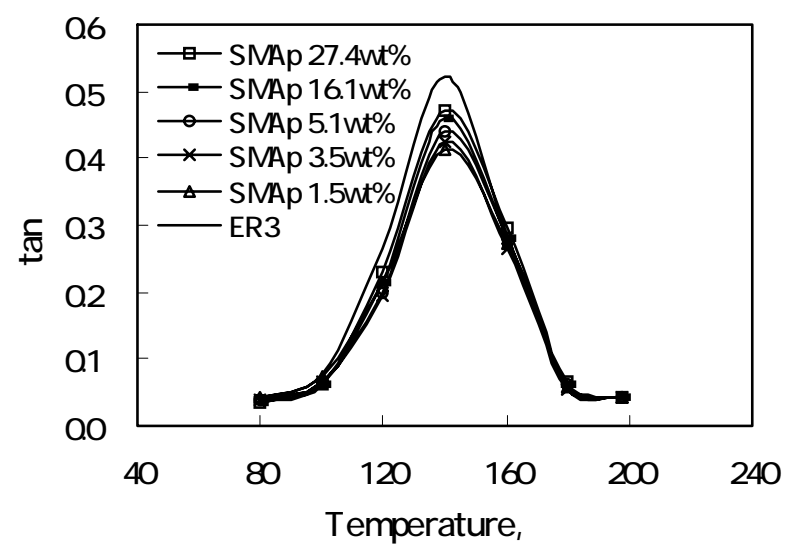

(b) SMA particle composites 
Figure 10

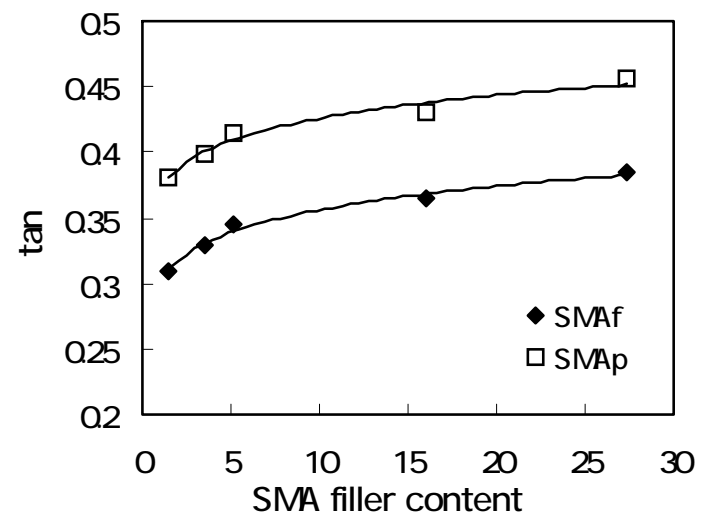


Table 1

\begin{tabular}{|c|c|c|c|c|c|c|}
\hline Materials & $\begin{array}{c}\text { Elastic } \\
\text { modulus } \\
(\mathrm{GPa})\end{array}$ & $\begin{array}{c}\text { Density } \\
\left(\mathrm{kg} / \mathrm{m}^{3}\right)\end{array}$ & $\begin{array}{c}\text { SMA size } \\
(\mathrm{mm})\end{array}$ & $\begin{array}{c}\text { Phase } \\
\text { transformation } \\
\text { temperature Af }\left({ }^{\circ} \mathrm{C}\right)\end{array}$ & $\begin{array}{c}\text { Poisson } \\
\text { Ratio } \\
(\mathrm{v})\end{array}$ & $\begin{array}{c}\text { Glass } \\
\text { Temperature } \\
\left({ }^{\circ} \mathrm{C}\right)\end{array}$ \\
\hline \multirow{2}{*}{ SMA } & $20.4\left(\mathrm{~T}<\mathrm{A}_{\mathrm{s}}\right)$ & 6500 & Particles 0.425 & 58 & 0.15 & - \\
\cline { 2 - 4 } & $71.4\left(\mathrm{~T}>\mathrm{A}_{\mathrm{f}}\right)$ & & Fiber $1.5 \sim 2$ & 58 & 0.3 & 140 \\
\hline \multirow{2}{*}{ ER3 } & - & 1150 & - & - & 0. & \\
\hline
\end{tabular}

